\title{
Psicologia Histórico-Cultural e Avaliação Psicológica: o processo ensino aprendizagem em questão
}

\author{
Psicologia Histórico-Cultural e Avaliação Psicológica
}

\author{
Marilda Gonçalves Dias Facci \\ Nilza Sanches Tessaro \\ Záira Fátima de Rezende Gonzalez Leal \\ Valéria Garcia da Silva \\ Cintia Godinho Roma
}

\begin{abstract}
Resumo
Este estudo teve por objetivo verificar a forma como tem sido desenvolvida a avaliação psicológica de crianças que apresentam dificuldades no processo de escolarização bem como analisar a contribuição dos pressupostos da Psicologia Histórico-Cultural nesse processo. Inicialmente, uma revisão bibliográfica sobre o tema da avaliação psicológica e sobre os conceitos fundamentais da Psicologia Histórico-Cultural, fundamentada no marxismo, foi realizada e, em seguida, entrevistas com doze profissionais de Psicologia que atuam na área escolar. Os principais resultados revelaram que os testes psicológicos têm sido os instrumentos mais utilizados no processo de avaliação psicológica, quando se trata da literatura brasileira, mas não mantiveram hegemonia entre os participantes deste estudo, o que se considera um avanço para a Psicologia escolar-educacional. Conclui-se, com esta pesquisa, que são necessários processos de avaliação que analisem o potencial dos sujeitos considerando o que se encontra na zona de desenvolvimento próximo. Palavras-chave: avaliação psicológica; aprendizagem; educação.
\end{abstract}

\section{Historical-Cultural Psychology and Psychological Evaluation: the teaching learning process in focus.}

\begin{abstract}
This study aimed, firstly, verifying the way psychological evaluation assists children who present difficulties during the educational process, and secondly, analyzing the contribution of Historical-cultural Psychology assumptions to that process. Initially, a bibliographical search on the theme 'psychological evaluation' and on fundamental concepts, concerning Historical-cultural Psychology, was carried out and afterwards, twelve psychological professionals, acting in schools, were interviewed. Regarding Brazilian specific literature on the subject, the main results revealed that psychological tests have been the instruments mostly used in the process of psychological evaluation. But, on the other hand, that procedure has not maintained hegemony among the participants during the investigation, what, in fact, is considered a progress for Psychology addressed to education. As a result, it was concluded that evaluation processes are necessary to analyze the potential of individuals considering all that is found in the zone of proximal development.
\end{abstract}

Keywords: psychological assessment; learning; education.

\section{Psicología Histórica-Cultural y Evaluación Psicológica: el proceso de enseñanza-aprendizaje en cuestión}

\begin{abstract}
Resumen
Este estudio tuvo como objetivo verificar la forma como viene siendo desarrollada la evaluación psicológica de niños que presentan dificultades en el proceso de escolarización, así como también analizar la contribución de los presupuestos de la Psicología Histórica-Cultural en ese proceso. Se realizó, inicialmente, una revisión bibliográfica sobre el tema de la evaluación psicológica y sobre los conceptos fundamentales de la Psicología Histórica-Cultural basada en el marxismo. En seguida fueron realizadas entrevistas con doce profesionales de Psicología que actúan en el área escolar. Los principales resultados revelaron que los testes psicológicos han sido los instrumentos más utilizados en el proceso de evaluación psicológica cuando se trata de la literatura brasileña, pero no mantuvieron una hegemonía entre los participantes de este estudio, lo que se considera un progreso para la Psicología escolareducacional. Con esta investigación se concluyó que son necesarios procesos de evaluación que analicen el potencial de los sujetos considerando lo que se encuentra en la zona de desarrollo próximo.
\end{abstract}

Palabras clave: evaluación psicológica; aprendizaje; educación. 


\section{Introdução}

Uma questão rotineira que se apresenta ao psicólogo escolar-educacional é a avaliação das queixas escolar, compreendida, conforme estudos de Souza (2000), como "problemas escolares" ou "distúrbios de comportamento e aprendizagem". Neste sentido, desenvolveu-se na Universidade Estadual de Maringá, uma pesquisa intitulada Psicologia HistóricoCultural e Avaliação Psicológica: o processo ensino aprendizagem em questão. Esse artigo versará sobre os resultados desta pesquisa.

O fracasso escolar defronta-se, ainda hoje, com elevado índice e, em muitos casos, os psicólogos são convocados a explicar as causas da não-aprendizagem das crianças. No Brasil, esse fracasso pode ser observado conforme dados oficiais do MEC/INEP (Brasil, 2003), na taxa de repetência no Ensino Básico, pois em 200 I somente $20,0 \%$ dos alunos do Ensino Fundamental foram aprovados.

Entender o porquê de a criança não aprender implica em analisar como se dá o processo inverso, ou seja, como ela aprende. Para essa compreensão, apoiar-se-á nas idéias de Vigotski', autor russo de fundamentação marxista, segundo o qual o aprendizado é um aspecto necessário e fundamental para que as funções psicológicas superiores se estabeleçam. Para Vigotski (2000), o indivíduo desenvolve-se, em parte, graças à maturação do organismo individual, mas é o aprendizado que provoca a interiorização da função psíquica; no entanto, essa visão não é predominante na atualidade e nem mesmo nos anos de 1920 e 1930. Nessa época, Vigotski (2000) considerava existirem pelo menos três grupos de teorias mais importantes referentes à relação entre desenvolvimento e aprendizagem.

O primeiro grupo de teorias parte da premissa de que desenvolvimento e aprendizagem são independentes. Esta idéia é bem representada na teoria de Piaget, que esclarece que a aprendizagem segue o desenvolvimento. O segundo grupo afirma que aprendizagem é desenvolvimento, e cada etapa de aprendizagem corresponde a uma etapa de desenvolvimento. Uma dessas teorias, elaborada por Willian James (18421910), baseia-se no conceito de reflexo. A terceira posição teórica, representada por Kurt Koffka (1846194I), tenta conciliar as teorias anteriores. Entende o autor que elas coexistem e que o desenvolvimento se baseia, de um lado, no processo de maturação, que depende do desenvolvimento do sistema nervoso, e de outro, no processo de aprendizado, que também é um processo de desenvolvimento. Aprendizagem é desenvolvimento; desenvolvimento é aprendizagem, e - desenvolvimento segue, pari passu, a instrução. Vigotski (2000) aponta essa relação de forma diferenciada, considerando que aprendizagem e desenvolvimento não constituem dois processos independentes, existindo entre eles relações complexas.

Atualmente, os Parâmetros Curriculares Nacionais (Brasil, 1997) trazem em sua fundamentação principalmente pressupostos piagetianos, que dão alicerce ao Construtivismo. No Construtivismo, além da Epistemologia Genética, aspectos da Aprendizagem Significativa de Ausubel, a Teoria das Emoções de Wallon e, principalmente, a Zona de Desenvolvimento Próximo de Vigotski são apresentados. Embora não seja objetivo deste texto polemizar essa questão, não se concorda com a defesa de que Vigotski e Piaget possam ser colocados como interacionistas, como se esses autores utilizassem o mesmo arcabouço teórico. Vigotski (2000) deixa muito claro que não coaduna com a forma que Piaget compreende a relação desenvolvimento e aprendizagem. Facci (2004) destaca que Vigotski analisa o desenvolvimento do psiquismo humano como atrelado às condições históricas em que o homem se desenvolve enquanto Piaget parte de um modelo biológico para a compreensão de desenvolvimento.

Em suas pesquisas, Vigotski (2000) identificou dois níveis de desenvolvimento: o real ou efetivo, que constitui as funções psicológicas já efetivadas, formadas e amadurecidas pelo indivíduo, como resultado de certos ciclos de desenvolvimento, identificados por meio da solução individual do problema; e o nível de desenvolvimento potencial, proximal ou próximo, defi-

\footnotetext{
I A grafia do nome desse autor na literatura tem sido apresentada de diversas formas. Adotar-se-á como padrão Vigotski, mas no caso de fazer-se referência a uma obra específica, será escrito da forma que aparece na obra.
} 
nido como aquelas funções em vias de amadurecimento, identificadas pela solução de tarefas com o auxílio de adultos e de outras crianças mais experientes. Enquanto aquele nível caracteriza o desenvolvimento mental retrospectivamente, este o caracteriza prospectivamente. Vygotski (1993, p. 239) esclarece que "... a zona de desenvolvimento próximo tem um valor mais direto para a dinâmica da instrução que - nível atual de seu desenvolvimento". O processo de desenvolvimento segue o processo de aprendizado e este é o responsável por criar a zona de desenvolvimento proximal; portanto, o ensino deve incidir sobre a zona de desenvolvimento proximal.

A escola tem como função trabalhar com os conceitos científicos, sistematizando e organizando os conteúdos, pois a apropriação destes conceitos, por parte dos alunos, concorre para a formação dos seus processos psicológicos superiores. Petroviski (1985) assevera que a escola deveria ter como um de seus objetivos desenvolver nos alunos as atividades mentais necessárias para a apropriação do conhecimento. Ela, como esclarece Saviani (2003), deve socializar os conteúdos já elaborados pela humanidade, de forma que os alunos possam participar do processo de humanização. Nesse processo, conforme observa Facci (2004), o professor tem papel destacado. Ele é o mediador entre o aluno e o conhecimento, por isso Ihe cabe intervir na zona de desenvolvimento proximal dos alunos e conduzir a prática pedagógica considerando a potencialidade de cada aluno. A mediação do professor implica, necessariamente, em ensinar.

Vigotski destaca que todos os indivíduos têm capacidade de se desenvolver desde que se elaborem mediações diferenciadas. Considera-se esse aspecto primordial; no entanto, a forma como as dificuldades de aprendizagem são compreendidas e avaliadas pode conduzir a estereotipias que nada fazem avançar na compreensão do desenvolvimento das funções psicológicas superiores dos alunos que apresentam queixas escolares, dificuldades essas que podem ser remetidas ao fracasso escolar.

Autores como Patto $(1997,2000)$, Moyses e Collares (1997), Mazzotti (2003), Souza (2000), Machado (2000), Angelucci, Kalmus, Paparelli e Patto (2004) têm pesquisado este tema e constatado que ora a criança é culpabilizada por não aprender, ora a família é destacada como responsável pelo insucesso escolar; por vezes, ainda, fatores intra-escolares são arrolados e o professor entra em cena como vilão. Angelucci e cols., (2004) analisaram 7I teses e dissertações, defendidas entre 1991 e 2002, na Faculdade de Educação e no Instituto de Psicologia da Universidade de São Paulo e chegaram à conclusão de que nesse período os estudos apresentam rupturas teórico-metodológicas, compreendendo-se o fracasso escolar da seguinte forma: como um problema psíquico, sendo o insucesso escolar decorrente de prejuízos da capacidade intelectual dos alunos, causados por problemas emocionais; como um problema técnico, culpabilizando o professor por não utilizar metodologias adequadas à aprendizagem dos alunos; como questão institucional, entendendo a escola como inserida em uma sociedade de classes regida pelos interesses do capital e, desta forma, as políticas públicas seriam responsáveis pelo fracasso escolar; como questão política, enfocando a cultura escolar, a cultura popular e relações de poder estabelecidas no interior da escola que privilegiam a cultura dominante em detrimento da cultura popular. Essas autoras demonstram que um dos aspectos presentes nos estudos sobre o fracasso escolar é o viés psicologizante, não contribuindo para o avanço do conhecimento acerca dessa problemática. As autoras constataram, ainda, a existência de uma outra vertente, com base materialista histórica do fracasso, iniciada em 1980, cujos autores apresentam uma revisão bibliográfica pautada em teorias críticas. No entanto, segundo as pesquisadoras, na hora de coletar os dados e selecionar os procedimentos adotados, os autores dos trabaIhos analisados contradizem o que enfocaram na fundamentação teórica das dissertações e teses, demonstrando, em muitas situações, superficialidade de conhecimento da teoria e métodos. As análises, de forma geral, são particularizadas, pois os profissionais têm realizado um processo de avaliação psicológica que contribui para a cristalização das explicações e, localizam no indivíduo, a culpa do seu insucesso na escola, patologizando um fenômeno que é social.

Considera-se, assim, que existe uma relação direta entre fracasso escolar e fracasso da sociedade capita- 
lista, pois se a escola não vai bem é porque a sociedade não vai bem. $O$ fracasso escolar é apenas um dos aspectos desta crise geral. Para compreender esse fenômeno, não se deve permanecer no limite do cotidiano da escola, e sim, buscar analisar as relações de determinação deste cotidiano, repleto de problemas, para compreender a totalidade do processo educacional, porque com ele estão imbricadas todas as questões da sociedade capitalista. Para se chegar à compreensão das formas de superação do entendimento, avaliação, encaminhamento e tratamento do fracasso escolar, identificado na escola como queixas escolares, é preciso estabelecer a relação entre escola e processo histórico.

No que se refere à atuação da Psicologia, constata-se que a introdução dessa ciência no processo educativo se deu por meio da Psicometria na avaliação psicológica, principalmente das queixas escolares. Alchieri e Cruz (2003) afirmam que a Psicologia se desenvolveu associada à sistematização dos processos psíquicos básicos e ao uso experimental de formas de medidas psicológicas que tinham como objetivo verificar os estágios de desenvolvimento e aprendizagem humana. A avaliação psicológica, conforme definição de Alchieri e Cruz (2003, p. 24), se refere ao "modo de conhecer fenômenos e processos psicológicos por meio de procedimentos e diagnóstico e prognóstico e, ao mesmo tempo, aos procedimentos de exame propriamente ditos para criar as condições de aferição ou dimensionamento dos fenômenos e processos psicológicos conhecidos". Os instrumentos de medida mais utilizados no processo de avaliação psicológica têm sido os testes, principalmente no que se refere à avaliação da inteligência. Segundo Dal Vesco, Mattos, Benicá e Tarasconi (1998) e Noronha, Primi e Alchieri (2005), no Brasil, o WISC é um dos instrumentos mais completos e conhecidos, disponíveis para avaliação global da inteligência.

Gerk-Carneiro e Neves Ferreira (1992) fizeram um estudo buscando identificar, na literatura brasileira, produzida na década de 1980, os métodos de avaliação de inteligência mais utilizados nas pesquisas empíricas, publicados em 7 periódicos nacionais. Esses autores constataram que a inteligência foi avaliada, nesse período, segundo três modelos teóricos: a aborgadem psicométrica, a desenvolvimentista e a cognitivista. Por outro lado, segundo pesquisas realizadas por Facci e Silva (2006) e Facci e Roma (2005, 2006), por meio de consultas a periódicos de Psicologia e Educação, a meta para localizar artigos que tratavam da avaliação das queixas escolares, quando se trata desse tema, a visão psicométrica é a que mais tem se destacado. Em pesquisas em 2488 artigos de periódicos de Psicologia, Facci e Silva (2006) constataram que somente $6,43 \%$ dos trabalhos continham, em suas referências, Piaget, destacando principalmente conteúdos relacionados à Teoria da Moralidade, noções físicas e matemáticas e desenvolvimento cognitivo, e não o processo de avaliação.

Facci e Roma (2005) constataram que a partir de 1980 foram poucas as produções que mencionaram os autores russos. Dos 3092 artigos pesquisados, apenas 122 continham em sua bibliografia pelo menos um ou mais de um ou os três autores russos Vigotski, Lúria e Leontiev. Assim, os artigos que apresentavam pelo menos um desses três autores, constituíram apenas 3,5\% do total de artigos pesquisados, e apenas $0,11 \%$ estava relacionado à questão da avaliação psicopedagógica. Em pesquisa posterior, as mesmas autoras (Facci \& Roma, 2006), ao analisarem 1663 artigos, concluíram que apenas 4,87\% continham em sua bibliografia pelo menos um ou mais de um ou os três autores russos. Os artigos que faziam menção a Piaget totalizaram 43 (2,58\%) e os que tratavam da avaliação psicológica foram apenas 15 $(0,90 \%)$.

Constatou-se, a partir das pesquisas mencionadas, que as queixas escolares têm sido pouco investigadas por psicólogos brasileiros e, quando analisadas, guardam em seu arcabouço a visão psicometrista já presente na origem da Psicologia na área educacional, que tinha como grande preocupação procurar as causas da não-aprendizagem utilizando recursos de testes psicológicos para medir inteligência. Partindo de uma abordagem psicométrica, pode-se remeter a uma concepção inatista do desenvolvimento, a qual, conforme menciona Rego (1995), se caracteriza por compreender que os fatores maturacionais e hereditários são responsáveis pela constituição do ser humano e do processo de conhecimento. Mesmo com a intro- 
dução do Construtivismo no contexto educacional brasileiro, principalmente a partir da década de 1990, que parte de um modelo interacionista piagetiano, analisando o desenvolvimento como decorrente da inter-relação entre indivíduo e meio ambiente, esse quadro no processo de avaliação não se alterou. Fica bastante contraditório constatar-se que a psicometria, e não o método clínico, tem servido de referência para os psicólogos realizarem o processo de avaliação das queixas escolares. No caso da psicometria não é possível compreender a influência das condições histórico-sociais no desenvolvimento da inteligência, questão defendida pela Psicologia HistóricoCultural, destacando quanto a aprendizagem promove o desenvolvimento.

Na realidade, segundo Machado (2000), tornouse "natural" acreditar na possibilidade de medir a inteligência; no entanto, a padronização dos testes psicológicos tem desconsiderado as desigualdades sociais e culturais existentes em nosso sistema capitalista, avaliando a capacidade individual das pessoas como se estas fossem construídas fora das relações sociais. Para essa autora, a queixa escolar é constituída de uma história coletiva e a avaliação implica em buscar alterar a produção dessa queixa. Beatón (200I), por sua vez, também critica a vulgarização e a prática anticientífica do uso dos testes; a falta de uma base teórica que fundamente os testes; a utilização de seus resultados somente para fazer diagnóstico, e não para propor alternativas de trabalho; a padronização inadequada para determinadas classes sociais; a utilização de testes somente para classificar e discriminar.

Geralmente, pode-se constatar na atualidade que o entendimento e atendimento das queixas escolares ainda são enviesados por uma visão tradicional da Psicologia, tendo como encaminhamento final as unidades básicas de saúde para sanar esse problema. Souza (2000) enfatiza que o encaminhamento para atendimento médico e psicológico das dificuldades de aprendizagem tem sido uma tônica presente nos meios escolares, sem uma análise ampla dos processos que produziram a queixa escolar. É com o processo que o psicólogo deve se preocupar, e sua intervenção, segundo Souza (2000, p. 127), deve primar por
“[...] pensar com a criança e com o professor essa relação estereotipada e produtora de repetência, da repetição de práticas que estigmatizam, excluem, oprimem e rotulam". Nesse sentido, Tanamachi e Meira (2003, p. 27) destacam que o psicólogo, ao lidar com as queixas escolares, deve fazer uma "análise da relação entre o processo de produção da queixa escolar e os processos de subjetivação/objetivação dos indivíduos nele envolvidos, como uma mediação necessária à superação das histórias de fracasso escolar", pois a "queixa" deve ser compreendida como uma "síntese de múltiplas determinações", dependendo da sua superação na ação conjunta de todos os aspectos envolvidos no processo de escolarização: relações familiares, grupos de amigos e contexto social e escolar.

Em termos gerais, o desenvolvimento das funções psicológicas e a aprendizagem de conteúdos são considerados como um fenômeno estanque, e não como um processo que acontece na interação entre professor, aluno e conhecimento. Neste sentido, concorda-se com Meira (2000, p. 57), quando afirma que "[...] parece que cada vez mais se evidencia a necessidade de se compreender a questão do desempenho escolar, contextualizando-o no âmbito de um processo maior", pois tal atitude ainda está muito longe de ser hegemônica entre os psicólogos. Não se pode, nesse aspecto, afirmar que todas as práticas psicológicas se desenvolvem dessa forma. Facci (1996), Souza (2000), Machado (2000), entre outros pesquisadores, têm buscado propor formas de avaliação psicológica que analisem as causas das queixas escolares como fruto das relações instituídas na escola, necessitando, portanto, do envolvimento mais amplo possível de professores, pais, equipe pedagógica e do próprio aluno na compreensão das problemáticas enfrentadas no processo de escolarização; no entanto, essa prática não é hegemônica entre os psicólogos.

A partir da década de 90 , outra forma de avaliação, denominada avaliação dinâmica (ou mediada, ou assistida) começou, também, a ser discutida no Brasil. De acordo com Lunt (1994, p. 232), esse tipo de avaliação "[...] envolve uma interação dinâmica entre examinador e aluno (examinado) com mais ênfase so- 
bre o processo do que sobre o produto da aprendizagem" (grifos do autor). Interessa, nesse aspecto, compreender "como" a criança aprende, ao invés de avaliar "o quê" ela já aprendeu. Linhares, Escolano e Enumo (2006, p. 16) propõem, também, esse tipo de avaliação assistida e afirmam:

"A idéia da avaliação assistida ou dinâmica, a qual defende a avaliação de 'processos' mais do que 'produtos' de aprendizagem, surgiu com a introdução da teoria de Vygotski por Brown e Ferrara, e das idéias de Reuven Feuerstein por C. Haywood, na Psicologia norte-americana atual. Originou-se de concepções teóricas sobre a plasticidade da cognição humana e da necessidade prática de encontrar novas medidas de diagnóstico para crianças que não se saiam bem em testes convencionais. Os conceitos de 'zona de desenvolvimento proximal' (ZDP), de Vygotski e a 'teoria de aprendizagem mediada' ou da 'experiência da aprendizagem mediada' (MLE), de Feüerstein, formam a base conceitual para elaboração da avaliação assistida ou dinâmica [...]".

A avaliação dinâmica pode complementar, mas não substituir os testes de Ql e sua contribuição mais significativa, de acordo com Linhares (1995), advém da possibilidade de fazer a sondagem da sensibilidade do examinando à instrução e identificar as estratégias cognitivas que ele usa para a solução de tarefas, permitindo verificar alterações no seu desempenho durante a situação de avaliação assim como estimar o potencial de transferência e generalização de aprendizagem. Pode-se afirmar, quanto a esse aspecto, que a avaliação é mediada pelo examinador, que fornece pistas e orienta o sujeito na realização das atividades. O conceito de aprendizagem mediada, de acordo com Linhares (1995), teve implicações significativas na área de avaliação do desempenho intelectual, buscando se apropriar dos conceitos de mediação e de zona de desenvolvimento próximo, elaborados por Vigotski.

No contexto de questionamentos dos testes padronizados de medida de desempenho e habilidades, os estudiosos soviéticos da escola de Vigotski propuseram a avaliação do potencial de aprendizagem por meio do método instrumental. Esse méto- do supera a concepção inatista, ambientalista e interacionista do desenvolvimento humano, pois para esses autores, as funções psicológicas superiores, tipicamente humanas (tais como a atenção voluntária, memória, abstração, comportamento intencional etc.), são produto da atividade cerebral e têm uma base biológica, mas, fundamentalmente, são resultantes da interação do indivíduo com o mundo, interação mediada pelos objetos construídos pelos homens.

Para Vigotski, que parte da base filosófica marxista, o traço fundamental da atividade humana é a mediação, através de instrumentos que se interpõem entre o sujeito e o objeto de sua atividade, instrumentos esses desenvolvidos pelo processo de trabalho. Vigotski (2004) enfatiza que todo e qualquer comportamento se transforma em uma operação intelectual, mediada por dois tipos de instrumento: instrumento psicológico e instrumento técnico. Uma diferença muito importante entre o instrumento psicológico e o técnico é a orientação do primeiro para a psique e o comportamento e do segundo para $\circ$ objeto externo, provocando modificações no objeto. O instrumento psicológico, ao contrário, é um meio de influir em si mesmo (ou em outro), mas não no objeto.

Vygotsky e Luria (1996, p. 183) afirmam que a capacidade de fazer uso de ferramentas torna-se um indicador do nível de desenvolvimento psicológico dos indivíduos, pois os "processos de aquisição de ferramentas, juntamente com o desenvolvimento específico dos métodos psicológicos internos e com a habilidade de organizar funcionalmente o próprio comportamento, é que caracterizam o desenvolvimento cultural da mente da criança".

De acordo com Vygotski (1995), o método instrumental pode ser muito útil para o estudo das funções psicológicas superiores. $O$ importante é fazer uma análise do processo, e não do objeto, e uma análise explicativa, e não descritiva; e, finalmente, a análise genética. Nesse sentido, é fundamental, nesse método, investigar os momentos iniciais do desenvolvimento das funções psicológicas superiores, numa perspectiva histórica, pois essas funções foram constituídas por diversos processos elementares e pri- 
mários do comportamento. O principal aspecto do método de análise psicológico, proposto por Vigotski, é estudar o todo, as propriedades e funções das partes que o integram, não como somatória das partes, mas possuindo propriedades particulares que 0 determinam.

A partir do método instrumental, a avaliação daqueles conhecimentos que estão no nível de desenvolvimento próximo é fundamental, ultrapassando as avaliações estáticas por meio de testes psicológicos de inteligência, que têm tido a preocupação de avaliar apenas o que se encontra no nível de desenvolvimento real do sujeito, desconsiderando, inclusive, o crescimento que este tem no próprio processo avaliativo.

Nesta introdução buscou-se destacar algumas visões presentes em relação a uma concepção de desenvolvimento e aprendizagem, passando por estudos sobre a queixa escolar e o processo de avaliação destas queixas e chegando a uma discussão de teorias que tratam dessa problemática, enfatizando pressupostos da escola de Vigotski.

Na seqüência, dar-se-á continuidade ao texto, desta vez apresentando o resultado de entrevistas, realizadas com psicólogos, cujo objetivo constituiu-se em verificar a forma como os profissionais realizam a avaliação psicológica de crianças que apresentam dificuldades no processo de escolarização.

\section{Método}

\section{Participantes}

Participaram desta pesquisa doze profissionais da área de Psicologia, sendo duas psicólogas escolares da rede particular de ensino; três supervisoras de estágio em Psicologia Escolar; duas psicólogas do Núcleo Regional de Ensino de Maringá; quatro psicólogas escolares de Rede Municipal de Ensino; um psicólogo de escola especial. Dos participantes, onze $(91,7 \%)$ são do gênero feminino e um do masculino, com idades variando entre 26 a 60 anos (um participante); $25 \%$ deles encontram-se na faixa etária de 26 a 30 anos e $66,8 \%$ entre 31 e 50 anos. Quanto à escolaridade, oito $(66,7 \%)$ possuem curso de pós- graduação latto sensu e dois stricto sensu (um mestrado e um doutorado). $O$ tempo de atuação profissional varia de um a trinta e cinco anos (um participante); $33,3 \%$ deles estão entre a faixa de um a cinco anos de experiência profissional, $25 \%$ de onze a quinze anos, $16,8 \%$ entre seis e dez anos; $8,3 \%$ possuem experiência entre as faixas que vão de dezesseis a vinte anos; também $8,3 \%$ de vinte e um a vinte cinco anos e, ainda, $8,3 \%$ para os que possuem de vinte seis a trinta anos de experiência na profissão.

\section{Material}

Durante a pesquisa, foram utilizados:

Termo de consentimento livre e esclarecido: entregue aos participantes para que pudessem confirmar o recebimento de informações sobre o objetivo do estudo e dar o seu consentimento para a participação na pesquisa;

Ficha de identificação dos participantes: por meio da qual foi possível obter dados relativos à idade, sexo, nível escolaridade etc;

Um questionário composto pelas seguintes questões:

Como você compreende o processo ensinoaprendizagem? Do seu ponto de vista, quais são as causas das dificuldades no processo de escolarização? Quais são os autores contemplados nos seus estudos sobre o processo de avaliação psicológica na escola? Que instrumentos, incluindo os testes psicológicos, você tem utilizado para avaliar as dificuldades no processo de escolarização? Após a avaliação, quais os procedimentos adotados para o encaminhamento e intervenção em relação às dificuldades no processo de escolarização?

\section{Procedimentos}

Inicialmente, realizou-se uma revisão bibliográfica sobre o tema da avaliação psicológica e sobre os conceitos fundamentais da Psicologia Histórico-Cultural com o objetivo de subsidiar a análise dos dados levantados junto aos participantes.

Em seguida, foram feitos os contatos com os profissionais por meio de telefone, pela coordenadora do Projeto, convidando-os a participar da pesquisa. Após, foi realizado um outro contato com 
os mesmos, para agendar o local e o horário para a aplicação do questionário. $\mathrm{Na}$ hora estabelecida, foi solicitado que os participantes preenchessem 0 termo de consentimento, momento também em que foram fornecidas as informações gerais do projeto assim como endereço de contato. Vale ressaltar ainda que o projeto foi aprovado pelo Comitê Permanente de Ética em Pesquisa Envolvendo Seres Humanos, da UEM, conforme Parecer no. I54/ 2003

Posteriormente ao consentimento de cada um deles, o questionário foi aplicado, sendo que alguns participantes optaram por respondê-lo oralmente e outros preferiram responder por escrito.

\section{Resultados e Discussão}

A organização dos dados foi feita com base nos questionários aplicados. Esses dados foram categorizados, apresentados em tabelas e discutidos/ analisados com base no referencial teórico, utilizado no presente estudo.
A Tabela I apresenta os dados relativos à concepção do processo ensino-aprendizagem, presente entre os participantes. Os resultados mostram que a concepção prevalente entre os participantes (25\%) foi a de que se trata de um processo que envolve um sujeito que ensina (professor), o aluno e o conhecimento; seguida da concepção que se refere a um processo que envolve planejamento, organização e mediação, considerando o aluno como ativo $(16,6 \%)$.

Destaca-se, entre as respostas fornecidas pelos profissionais, diversidade na compreensão do processo ensino-aprendizagem, passando por aspectos que vão desde uma visão vigotskiana, uma visão piagetiana, incluindo ainda uma visão comportamental. Esta diversidade foi também constatada por Vigotski (2000), que por volta de 1930, identificou algumas concepções de desenvolvimento e aprendizagem presentes, as quais continuam até hoje norteando o trabalho do psicólogo na escola.

Considera-se que uma questão fundamental para a atuação do psicólogo escolar-educacional é ter clareza acerca da concepção teórica sobre a rela-

Tabela I - Como você compreende o processo ensino-aprendizagem

\begin{tabular}{lcc}
\hline CATEGORIAS & F & $\%$ \\
\hline $\begin{array}{l}\text { Processo que envolve um sujeito que ensina (professor), o aluno e o } \\
\text { conhecimento }\end{array}$ & 3 & 25,0 \\
\hline $\begin{array}{l}\text { Processo que envolve planejamento, organização e mediação, considerando } \\
\text { o aluno como ativo }\end{array}$ & 2 & 16,6 \\
\hline $\begin{array}{l}\text { Desenvolvimento de habilidades acadêmicas } \\
\text { Processo onde os indivíduos estão em constante transformação }\end{array}$ & 1 & 8,3 \\
\hline $\begin{array}{l}\text { Processo que implica e requer interação para que haja transformação } \\
\text { cognitivo-social do sujeito que aprende e que ensina }\end{array}$ & 1 & 8,3 \\
\hline $\begin{array}{l}\text { Compreende a estimulação das funções cognitivas, sociais e físicas que } \\
\text { produzem o desenvolvimento dessas funções }\end{array}$ & 1 & 8,3 \\
\hline $\begin{array}{l}\text { Compreensão do processo ensino-aprendizagem a partir de uma visão } \\
\text { sistêmica }\end{array}$ & 1 & 8,3 \\
\hline $\begin{array}{l}\text { Envolve um trabalho com a consciência fonológica da criança } \\
\text { Estimulação do ambiente sobre o indivíduo com maturação necessária, com } \\
\text { objetivo de mudanças de comportamento. Desenvolvimento resulta de } \\
\text { complexas interaçôs/mediações entre hereditário e meio }\end{array}$ & 1 & 8,3 \\
\hline
\end{tabular}


ção desenvolvimento e aprendizagem, pois somente desta forma empreenderá práticas consistentes já que sua ação reflete sua concepção e as escolhas quanto à metodologia a ser utilizada em seu trabalho. Não obstante, a partir da análise desta questão e das respostas dos participantes como um todo, não se pode afirmar que estes tenham clareza quanto aos fundamentos teórico-metodológicos, utilizados em seu trabalho. Isso pode ser exemplificado pelos autores contemplados nos estudos empreendidos pelos participantes da pesquisa, que citam, quando se trata da avaliação psicológica na escola, autores de correntes teóricas bem diversas, colocando-os lado a lado.

Os dados apresentados na Tabela 2 revelam que os autores mais citados pelos participantes foram tam da questão da Psicologia e da Educação assim como recorrem, muitas vezes, a autores de outras linhas da Psicologia, como a psicanálise e a análise comportamental. Foram, ainda, arrolados autores que escrevem sobre educação em uma vertente crítica da Psicologia Escolar-Educacional sobre problemas e distúrbios de aprendizagem.

O que merece ser destacado é a grande indicação de autores da psicologia da escola russa para a compreensão do processo de avaliação psicológica na escola, o que se contrapõe às pesquisas realizadas por Facci e Silva (2006), Facci e Roma (2005, 2006), que constataram, nos artigos analisados em periódicos de psicologia e educação, pouca utilização, nas referências, de autores da Psicologia Histórico-Cultural e grande ênfase na psicometria.

Tabela 2 - Quais são os autores contemplados nos seus estudos sobre o processo de avaliação psicológica na escola?

\begin{tabular}{lcc}
\hline CATEGORIAS & F & $\%$ \\
\hline Luria, Leontiev, Vigotski, Davidof, ..., ..., (autores russos) & 10 & 14,93 \\
Marilene Proença, Adriana Marcondes, Moysés e Collares & 2 & 3,00 \\
Maria Helena de Souza Patto & 2 & 3,00 \\
Newton Duarte & 2 & 3,00 \\
Piaget & 4 & 6,00 \\
Bassedas & 2 & 3,00 \\
Winnicott & 2 & 3,00 \\
Outros & 43 & 64,07 \\
\hline Total & 67 & 100,00 \\
\hline
\end{tabular}

Luria, Leontiev, Vigotski, Davidov com 14,3\% das respostas.

O que se pode constatar é que Piaget e Vigotski foram os autores mais pesquisados ou lidos pelos participantes da pesquisa. Torna-se importante destacar, neste momento, que os Parâmetros Curriculares Nacionais (Brasil, 1997), documento que norteia o processo pedagógico na escola, também trazem em sua fundamentação idéias desses autores, o que sugere que os sujeitos estão se embasando, de forma geral, nesses autores que tra-
Em relação às causas das dificuldades no processo de escolarização, a Tabela 3 aponta maior consenso entre os participantes. Das respostas, $43,6 \%$ referem-se às causas das dificuldades no processo de escolarização como oriundas de fatores intra-escolares, como formação do professor, vínculo entre professor e aluno, adequação e adaptação curricular, métodos e objetivos do ensino. Os fatores extrínsecos - tais como falta de estimulação visual, condições sócio-econômicas e culturais desfavoráveis da família se refletindo no desempenho escolar dos alunos - apa- 
Tabela 3 - Do seu ponto de vista, quais são as causas das dificuldades no processo de escolarização?

\begin{tabular}{lcc}
\hline CATEGORIAS & F & $\%$ \\
\hline $\begin{array}{l}\text { Fatores extrínsecos: estimulação visual, sócio-econômico-cultural da } \\
\text { família, condições ambientais desfavoráveis, metodologias de ensino } \\
\text { não apropriadas }\end{array}$ & 6 & 26,1 \\
\hline $\begin{array}{l}\text { Fatores intra-escolares: formação do professor, vínculo professor- } \\
\text { aluno, adequação e adaptação curricular, método e objetivo do ensino }\end{array}$ & 10 & 43,6 \\
\hline Falta de envolvimento do psicólogo no processo ensino-aprendizagem & 1 & 4,3 \\
\hline Causas vinculadas a totalidade histórico-social & 1 & 4,3 \\
\hline Vinculado aos fatores sociais & 2 & 8,7 \\
\hline Falta de recursos & 2 & 8,7 \\
\hline Falta de condições da escola (prof. auxiliar, contraturno) & 1 & 4,3 \\
\hline Total & 23 & 100 \\
\hline
\end{tabular}

recem com um percentual de $26,1 \%$. Alguns participantes atribuem as dificuldades a fatores sociais $(8,7 \%$ das respostas), outros consideram que o problema é a falta de recursos $(8,7 \%)$. Outras explicações fornecidas pelos participantes remetem-se à falta de envolvimento do psicólogo no processo ensino-aprendizagem; causas vinculadas à totalidade histórico-social; à falta de condições da escola (professor auxiliar, contraturno); a fatores intrínsecos, que se referem a aspectos individuais, como deficiências, síndromes, dificuldades cognitivas, problemas do desenvolvimento socio-emocional, aspectos neuropsicológicos.

Reportando-se ao artigo de Angelucci e cols. (2004), observa-se que as respostas dos participantes também refletem a presença de rupturas teórico-metodológicas, tal como a pesquisa realizada por aquelas autoras que apresentam as causas do insucesso escolar como decorrentes de problemas psíquicos, extrínsecos aos alunos. Para tanto, partem do princípio de que o insucesso escolar é decorrente de prejuízos da capacidade intelectual dos alunos oriundos de problemas emocionais, ou resulta de fatores intra-escolares. Algumas consideram o fracasso escolar como questão institucional, decorrente de a escola estar inserida em uma sociedade capitalista. O viés psicologizante, de que tratam Angelucci e cols. (2004), parece estar presente na amostra pesquisada na qual muito pouco se levam em consideração os determinantes histórico-sociais que produzem o fracasso escolar.

Os dados, apresentados na Tabela 4, demonstram que dentre os instrumentos, incluindo os testes psicológicos, utilizados para avaliar as dificuldades no processo de escolarização, a entrevista com pais e a anamnese aparecem com a maior freqüência de respostas (14,1\%), seguindo-se observação do aluno na escola $(12,5 \%)$ e análise do desempenho escolar por meio de materiais produzidos pelos alunos (10,9\%). Esses procedimentos foram os mais freqüentes na indicação dos participantes, mas são citados, ainda, outros, conforme a Tabela.

Recorrendo mais uma vez à pesquisa de Facci e Silva (2006) e Facci e Roma (2005, 2006), as autoras constataram que existe predominância de uma visão psicométrica na avaliação das queixas escolares. No entanto, esse grupo de psicólogos parece, de certa forma, avançar em relação a este aspecto, buscando outros procedimentos, como entrevistas com pais, com a criança e com o professor, observações em sala de aula, análise do desempenho escolar, entre outros recursos, para analisar o potencial de aprendizagem dos alunos.

Os dados da Tabela 5 demonstram que os testes mais utilizados pelos participantes são o teste de in- 
Tabela 4 - Que instrumentos, incluindo os testes psicológicos, você tem utilizado para avaliar as dificuldades no processo de escolarização?

\begin{tabular}{|c|c|c|}
\hline CATEGORIAS & $\mathrm{F}$ & $\%$ \\
\hline $\begin{array}{l}\text { Análise do desempenho escolar, por meio de materiais produzidos } \\
\text { pelos alunos }\end{array}$ & 7 & 10,9 \\
\hline Entrevista com professor & 5 & 7,82 \\
\hline Entrevista com equipe pedagógica & 2 & 3,12 \\
\hline Entrevista com pais, anamnese & 9 & 14,1 \\
\hline Utilização de testes psicométricos & 5 & 7,82 \\
\hline Provas pedagógicas - leitura, escrita, matemática & 3 & 4,7 \\
\hline Entrevista com alunos & 5 & 7,82 \\
\hline Desenho livre & 2 & 3,12 \\
\hline Atividades lúdicas e jogos & 3 & 4,7 \\
\hline Observação do aluno na escola & 8 & 12,5 \\
\hline $\begin{array}{l}\text { Coleta de dados da criança na escola por meio de ficha de } \\
\text { encaminhamento }\end{array}$ & 1 & 1,56 \\
\hline $\begin{array}{l}\text { Realização de reunião avaliadora com equipe pedagógica, professores, } \\
\text { coordenadores S. E., psicóloga e coordenadora Ed. Especial }\end{array}$ & 2 & 3,12 \\
\hline Análise do comportamento operante da criança & 1 & 1,56 \\
\hline Provas psicomotoras & 1 & 1,56 \\
\hline Análise de laudos médicos & 1 & 1,56 \\
\hline Teste de Desempenho Escolar - TDE & 1 & 1,56 \\
\hline Observação da relação professor/aluno & 1 & 1,56 \\
\hline Reunião com a equipe pedagógica da escola & 2 & 3,12 \\
\hline Realização de atividades artísticas & 1 & 1,56 \\
\hline Orientação ao professor e à família & 1 & 1,56 \\
\hline Capacitação docente sobre o desenvolvimento da criança & 1 & 1,56 \\
\hline Provas Piagetianas & 1 & 1,56 \\
\hline Provas e avaliação psicopedagógica & 1 & 1,56 \\
\hline Total & 64 & 100,00 \\
\hline
\end{tabular}

teligência WISC (27,6\%), ○ Teste Gestáltico Visomotor - Bender (13,9\%), o Colúmbia (13,9\%), seguidos pelos testes Raven (7\%) e as Provas Piagetianas (7\%). Outros testes também foram citados, porém com menor freqüência. A maioria dos psicólogos entrevistados utiliza mais de um teste, de forma combinada.

Entretanto, é importante destacar que, segundo Gerk-Carneiro e Neves-Ferreira (1992), a psicometria constitui-se como um modelo teó- 
Tabela 5 - Testes Psicológicos

\begin{tabular}{lcr}
\hline CATEGORIAS & F & $\%$ \\
\hline Wisc & 8 & 27,6 \\
Raven & 2 & 7,0 \\
Bender & 4 & 13,9 \\
Rey - Aprendizagem auditiva verbal & 1 & 3,4 \\
STROOPT - Atenção concentrada e controle inibitório & 1 & 3,4 \\
TDE & 1 & 3,4 \\
Colúmbia & 4 & 13,9 \\
Figura Humana & 1 & 3,4 \\
Provas Projetivas Psicopedagógicas & 1 & 3,4 \\
Faz de Conta & 1 & 3,4 \\
HTP & 1 & 3,4 \\
RAULT (memória) & 1 & 3,4 \\
Provas Piagetianas & 2 & 7,0 \\
Escala de TDAH - versão para professores - Benczik & 1 & 3,4 \\
\hline Total & 29 & 100,0 \\
\hline
\end{tabular}

rico para avaliação de inteligência na literatura brasileira e não ocupa lugar de destaque entre os sujeitos entrevistados. Quando estes recorrem à aplicação de testes, constata-se que o Wisc é mais utilizado. Este fato demonstra haver uma certa hegemonia entre os brasileiros, conforme observam Dal Vesco e cols. (1998), Noronha e cols. (2005).

Em relação aos procedimentos adotados para o encaminhamento e intervenção relativos às dificuldades no processo de escolarização, os participantes demonstraram utilizar mais de um procedimento de forma combinada. A Tabela 6 mostra que 20\% das respostas dos participantes dizem respeito ao encaminhamento do aluno para a área de saúde. Além desse procedimento, o que aparece em seguida é a devolução à escola, envolvendo a professora e a equipe pedagógica (13,4\%). São utilizados, também, encaminhamentos para trabalho psicopedagógico $(6,8 \%)$; entrega de relatório sobre o aluno avaliado para a escola $(6,8 \%)$; devolução em conjunto para a família, a escola e a criança
$(6,8 \%)$. Outros procedimentos são também utilizados em menor freqüência, como se observa na Tabela 6.

Neste aspecto vale recorrer aos estudos desenvolvidos por Souza (2000), pois concluiu que a maioria dos encaminhamentos feitos aos profissionais de Psicologia em unidades básicas de saúde apresenta como queixa os problemas de aprendizagem das crianças. Por esta amostra, pode-se dizer que boa parte dos psicólogos entrevistados continua, ainda, encaminhando crianças com queixas escolares para essas unidades. Está certo que se deve ressaltar positivamente a preocupação em envolver a escola na devolução do processo de avaliação, mas não se pode deixar de questionar até que ponto se tem prestado um serviço de apoio a crianças no próprio espaço escolar. Compreende-se que tal encaminhamento implicaria na utilização de recursos externos à possibilidade de intervenção da Psicologia, mas não se pode deixar de mencionar quanto as escolas precisam se organizar melhor para que todas as crianças se apropriem do conhecimento. 
Tabela 6 - Após a avaliação, quais os procedimentos adotados para o encaminhamento e intervenção em relação às dificuldades no processo de escolarização?

\begin{tabular}{llc}
\hline CATEGORIAS & F & $\%$ \\
\hline Encaminhamento para trabalho psicopedagógico & 2 & 6,8 \\
Discussão dos resultados com a coordenação de educação especial & 1 & 3,3 \\
Devolutiva para a família & 1 & 3,3 \\
Devolutiva para a escola: professora e equipe pedagógica & 4 & 13,4 \\
Entrega do relatório do aluno avaliado para a escola & 2 & 6,8 \\
Encaminhamento para a educação especial & 1 & 3,3 \\
Encaminhamento para a área de saúde & 6 & 20 \\
Não realiza intervenção direta com a criança, apenas realiza o & & 3,3 \\
encaminhamento & 1 & 6,8 \\
Devolução em conjunto: família, escola e criança & 2 & 3,3 \\
Acompanhamento aos alunos na escola & 1 & 3,3 \\
Atendimento à criança utilizando a teoria do reforço & 1 & 3,3 \\
Desenvolvimento de atividades em sala de aula & 1 & 3,3 \\
Reuniões com a equipe de Educação Especial do Núcleo & 1 & 3,3 \\
Estudos com os professores & 1 & 3,3 \\
Orientação aos professores quanto a metodologias de ensino & 1 & 3,3 \\
Orientação conjunta: psicólogo, supervisor pedagógico e professor & 1 & 3,3 \\
Encaminhamento ao contraturno e grupo psicopedagógico & 1 & 3,3 \\
Encaminhamento a outros profissionais: médico, fonoaudióloga, & 1 & 3,3 \\
psicólogo clínico & 1 & 100,0 \\
\hline Orientação ao professor & 30 & \\
\hline Total & & 1 \\
\hline
\end{tabular}

\section{Considerações Finais}

Durante a pesquisa bibliográfica foi possível não só conhecer práticas exercidas por psicólogos escolares no Brasil como também procedimentos e instrumentos utilizados para avaliação de queixas escolares, assim como ter acesso a aspectos teóricos relacionados à compreensão das queixas escolares e avaliação psicológica. Foi também possível analisar várias produções teóricas que tinham como pressuposto a Psicologia Histórico-Cultural.

De forma geral, verifica-se na literatura estudada a presença de pelo menos três linhas de estudo da ava- liação psicológica na escola: uma que defende o uso dos testes psicológicos padronizados, sendo a Psicometria o método adotado; outra que defende a utilização de testes psicológicos, mas utiliza o recurso da mediação, pautado nos pressupostos vigotskianos, tratando-se, portanto de avaliação mediada ou assistida, e uma terceira que utiliza outros recursos como entrevistas com professores, com as famílias e com as próprias crianças, atividades realizadas pelos alunos, observações no contexto escolar, análise dos fatores intra-escolares, assim como outros aspectos. Entre os participantes deste estudo não foi possível identificar nenhuma destas três ten- 
dências citadas, visto que se observou uma utilização combinada de diversos instrumentos, ampliando o uso de testes padronizados com outras atividades nãoformais para lidar com as queixas escolares encontradas em seu cotidiano.

Pode-se inferir que as críticas formuladas no decorrer dos anos aos testes psicológicos provavelmente influenciaram os psicólogos entrevistados, provocando a busca de outras estratégias para analisar as queixas escolares de modo a fugirem do uso exclusivo dos testes. Machado (2000) e Molyses e Collares (1997) e Beatón (200I), conforme abordou-se no decorrer deste artigo, têm questionado o uso exclusivo de teste. De acordo com os estudos realizados acerca da Psicologia Histórico-Cultural, utilizando o método instrumental, não interessa estudar uma função psicológica isolada no processo de avaliação psicológica, mas sim, o funcionamento conjunto dessas funções, em atividades diversificadas. Não se trata de analisar o repertório de conhecimentos já adquiridos pela criança, e sim os recursos que ela utiliza para responder a uma questão. No caso da avaliação através de testes psicológicos padronizados não é possível compreender a influência das condições histórico-sociais no desenvolvimento da inteligência, questão defendida pela Psicologia Histórico-Cultural, destacando quanto a aprendizagem promove o desenvolvimento.

Não se pode deixar de mencionar, aqui, a mediação do avaliador, pois quando esta é utilizada e pistas são fornecidas ao indivíduo, podem-se ter resultados diferentes daqueles obtidos quando este realiza a atividade, sozinho. No entanto, não basta apenas mediar a aplicação dos testes psicológicos, tão questionados por diversos psicólogos. É importante estudar a origem de determinado comportamento, como se deu seu desenvolvimento e que fatores condicionaram sua manifestação.

Os resultados da pesquisa demonstram que os autores citados com mais freqüência pelos participantes são integrantes da Escola de Vigotski, ou Teoria Histórico-Cultural, porém a utilização de estratégias e instrumentos para realizar a avaliação das queixas escolares não mostra serem considerados os pressupostos desta vertente teórica, uma vez que, nesta perspectiva, a avaliação deve compreender como a criança está mediando suas respostas. Faz-se necessário investigar o seu comportamento e desenvolvimento por meio da descoberta dos instrumentos psicológicos que ela mesma emprega.

Neste estudo, observou-se, ainda, que as causas das dificuldades no processo de escolarização devemse, para muitos participantes, a fatores intra-escolares, como formação do professor, vínculo entre professor e aluno, adequação e adaptação curricular, métodos e objetivos do ensino. Apesar de considerarem estes fatores, os participantes continuam a buscar, na própria criança, as justificativas para suas dificuldades uma vez que continuam a utilizar amplamente testes e outros procedimentos do gênero. Neste aspecto, podem-se retomar os estudos realizados por Angelucci e cols. (2004) que destacam o quanto o viés psicologizante ainda está presente nas explicações acerca do fracasso escolar influenciado, principalmente, por uma visão ideológica pautada no liberalismo que coloca no indivíduo a responsabilidade pelo seu sucesso ou fracasso, desconsiderando a divisão de classes sociais, fruto do capitalismo, que pelas relações sociais estabelecidas diferenciam os indivíduos, não dando a todos as mesmas condições para o desenvolvimento de todas suas potencialidades, inclusive a de se apropriar do conhecimento.

Constatou-se que, após a realização da avaliação da queixa escolar, o procedimento mais utilizado para o encaminhamento e intervenção, pelos participantes, foi o encaminhamento do aluno para a área da saúde, o que reforça a concepção de que as dificuldades encontram-se na própria criança, o que estaria de acordo com uma concepção inatista de desenvolvimento, a qual, conforme menciona Rego (1995), se caracteriza por compreender que os fatores maturacionais e hereditários são responsáveis pela constituição do ser humano e do processo de conhecimento.

Destaca-se, neste momento, que aqui tem se defendido que a análise do desenvolvimento da criança, das suas dificuldades e potencialidades, deve ser permeada por uma compreensão de que o sucesso escolar depende de mudanças estruturais que dêem destaque à educação e à escola, na transmissão dos conhecimentos científicos. Partindo das idéias de 
Vigotski, Facci (2004) ressalta quanto a apropriação dos conhecimentos científicos provoca o desenvolvimento das funções psicológicas superiores. Destarte, a escola deve criar meios para que esses conhecimentos sejam apropriados por todos os indivíduos que passam pelos bancos escolares.

Para finalizar, considerando a perspectiva Histórico-cultural na avaliação psicológica das queixas escolares, é importante salientar como analisar a história da produção da queixa, o contexto em que ela foi produzida, as medidas pedagógicas tomadas para a superação das dificuldades e as superações já alcançadas em relação às dificuldades apresentadas pelos alunos. Envolver equipe pedagógica, professores e pais no processo de avaliação é primordial, de forma que todos possam auxiliar na compreensão e na avaliação da potencialidade da criança; na utilização de testes psicológicos como complemento da avaliação e não como critério de classificação e discriminação.

Por fim, fazer uma avaliação analisando todos os aspectos que podem estar interferindo na apropriação do conhecimento pelo aluno, considerando as condições histórico-sociais, fatores intra-escolares e a dinâmica de funcionamento psicológico do aluno, compreendendo a avaliação como o início de uma intervenção que deve contribuir para o processo de humanização.

\section{Referências}

Alchieri, J. C., \& Cruz, R. M. (2003). Avaliação Psicológica: conceitos, métodos e instrumentos. São Paulo: Casa do Psicólogo.

Angelucci, C. B., Kalmus, J., P., Paparelli, R., \& Patto, M. H. S. (2004). O estado da arte da pesquisa sobre o fracasso escolar ( 199 |-2002): um estudo introdutório. Educação em Pesquisa, $30(1), 51-72$.

Beatón, G. A. (200I). Evaluación y Diagnóstico en la Educación y el Desarrollo desde el enfoque Histórico-Cultural. São Paulo: Laura Marisa C. Calejón.

Brasil (1997). Ministério da Educação e do Desporto Secretaria de Educação Fundamental. Parâmetros curriculares nacionais. Brasília.
Brasil (2003). Ministério da Educação. Ensino Básico - Taxa de repetência por série - 198I-200I. Brasil. Disponível: www.inep.goc.br/download/informativo/2003/taxarepetência.xls. Recuperado: 25 out. 2003.

Dal Vesco, A., Mattos, D., Benicá, C., \& Tarasconi, C. (1998). Correlação entre WISC e rendimento escolar na escola pública e na escola particular. Psicologia: Reflexão e Crísica, I I (3), 48 I-495.

Facci, M. G. D. (2004). Valorização ou esvaziamento do trabaIho do professor? Um estudo crítico-comparativo da teoria do professor reflexivo, do construtivismo e da psicologia vigotskiana. Campinas: Autores Associados.

Facci, M. G. D., \& Roma, C. G. (2005). O método instrumental de Vigotski e a avaliação psicológica. Relatório final de Projeto de Iniciação Científica. Maringá, UEM. Mimeo.

Facci, M. G. D., \& Roma, C. G. (2006). A avaliação psicológica das queixas escolares. Relatório final de Projeto de Iniciação Científica. Maringá, UEM. Mimeo.

Facci, M. G. D., \& Silva, V. G. (2006). Problemas de escolarização e avaliação psicopedagógica: a visão de pesquisadores e psicólogos. Relatório final de Projeto de Iniciação Científica. Maringá, UEM. Mimeo.

Facci, M. G. D., Marchi, E. L., Bega, R. M. A. P., Brogim, R., Plepis, R. S., \& Sguarezi, S. M. F. D. (1996). Psicologia e a escola pública: a atuação do setor de psicologia no município de Maringá. Psicologia em Estudo, I(I)205-2I 2.

Gerke-Carneiro, E., \& Neves-Ferreira, I. C. (1992). Avaliação da inteligência segundo diferentes modelos: a situação brasileira. Arquivos Brasileiros de Psicologia, 44(3/4), I57-I 94.

Linhares, M. B. M. (1995). Avaliação Assistida: fundamentos, definição, característica e implicações para a avaliação psicológica. Psicologia: Teoria e Pesquisa, I I(I), I3-22.

Linhares, M. B. M., Escolano, A. C. M., \& Enumo, S. R. F. (2006). Avaliação assistida: fundamentos, procedimentos e aplicabilidade. São Paulo: Casa do Psicólogo.

Lunt, I. (1994). A prática de avaliação. Em H. Daniel (Org.), Vygotsky em foco: pressupostos e desdobramentos (pp. 219-252). Campinas: Papirus.

Machado, A. M. (2000). Avaliação psicológica na educação: mudanças necessárias. Em E. R. Tanamachi, M. L. Rocha \& M. P. R. Proença (Orgs.), Psicologia e Educação: desafios teóricopráticos (pp. 143-167). São Paulo: Casa do Psicólogo.

Mazzotti, A. J. A. (2003). "Fracasso Escolar”: representações de professores e de alunos repetentes. Anais da $26^{a}$ Reunião 
Anual da ANPEd (pp.l-I7). Poços de Caldas: local onde foi realizado o encontro.

Meira, M. E. M. (2000). Psicologia Escolar: pensamento crítico e práticas profissionais. Em E. R. Tanamachi, M. L. Rocha \& M. P. R. Proença (Orgs.), Psicologia e Educação: desafios teóricopráticos (pp. 35-72). São Paulo: Casa do Psicólogo.

Moyses, M. A. A., \& Collares, C. A. L. (1997). Inteligência Abstraída, Crianças Silenciadas: as Avaliações de Inteligência. Psicologia USP, 8(I), 63-89.

Noronha, A. P. P., Primi, R., \& Alchieri, J. C. (2005). Instrumentos de avaliação mais conhecidos/utilizados por psicólogos e estudantes de psicologia. Psicologia: Reflexão e Crítica, I8(3), 390-40I.

Patto, Maria Helena Souza (1997). Para uma Crítica da Razão Psicométrica. Psicologia USP, 8(I), 47-62.

Patto, M. H. S. (2000). A produção do fracasso escolar: histórias de submissão e rebeldia. (2a ed.). São Paulo: Casa do Psicólogo.

Rego, T. C. (1995). Vygotsky: uma perspectiva histórico-cultural da educação. ( $2^{\mathrm{a}}$ ed.). Petrópolis: Vozes.

Saviani, D. (2003). Pedagogia histórico-crítica: primeiras aproximações. ( $8^{\mathrm{a}}$ ed.). Campinas: Cortez - Autores Associados.
Souza, M. P. R. (2000). A queixa escolar na formação de psicólogos: desafios e perspectivas. Em E. R. Tanamachi, M. L. Rocha \& M. P. R. Proença (Orgs.), Psicologia e Educação: desafios teórico-práticos (pp. 105-142). São Paulo: Casa do Psicólogo.

Tanamachi, E. R., \& Meira, M. E. M. (2003). A atuação do psicólogo como expressão do pensamento crítico em Psicologia da Educação. Em M. E. M. Meira \& M. A. M. Antunes (Orgs.), Psicologia Escolar: práticas críticas (pp. I I-62). São Paulo: Casa do Psicólogo.

Vygoski, L. S. (1993). Obras escogidas II. Madrid: Centro de Publicaciones del M.E.C. y Visor Distribuciones.

Vygoski, L. S. (1995). Obras escogidas III. Madrid: Centro de Publicaciones del M.E.C. y Visor Distribuciones.

Vigotski, L. S. (2000). A Construção do Pensamento e da Linguagem. São Paulo: Martins Fontes.

Vigotski, L. S. (2004). Teoria e método em psicologia. ( $3^{\mathrm{a}}$ ed.). São Paulo: Martins Fontes.

Vygotsky, L. S., \& Luria, A. R. (1996). Estudos sobre a história do comportamento: símios, homem primitivo e criança. Porto Alegre: Artes Médicas.

Recebido em: 04/04/2007

Revisado em: 26/12/2007

Aprovado em: 17/01/2008

Sobre as autoras

Marilda Gonçalves Dias Facci (marildafacci@wnet.com.b) - Doutora em Educação Escolar pela UNPES/Araraquara; professora do curso de Psicologia da Universidade Estadual de Maringá-UEM e do Programa de Pós-Graduação em Psicologia-PPI; coordenadora do Programa de Pós-Graduação em Psicologia/UEM.

Nilza Sanches Tessaro Leonardo - Doutora em Psicologia pela PUC/Campinas; professora do curso de Psicologia da Universidade Estadual de Maringá -UEM e do Programa de Pós-Graduação em Psicologia-PPI

Záira Fátima de Rezende Gonzalez Leal - Mestre em Educação pela UNESP/Marília; doutoranda em Psicologia na USP/SP, professora do curso de Psicologia da Universidade Estadual de Maringá-UEM

Valéria Garcia da Silva - Aluna do curso de Psicologia da Universidade Estadual de Maringá-UEM

Cintia Godinho Roma - Aluna do curso de Psicologia da Universidade Estadual de Maringá-UEM

Endereço para correspondência

Marilda Gonçalves Dias Facci

Rua Parque do Horto, 124, Jardim Parque do Horto

Fone: (44) 326I-44I6 (UEM)

CEP: 87.060-285 - Maringá-PR

e-mail: marildafacci@wnet.com.br 